\title{
Molecular and clinical analysis of TRPC6 and AGTR1 genes in patients with pulmonary arterial hypertension
}

\author{
Guillermo Pousada ${ }^{1,2}$, Adolfo Baloira $^{3}$ and Diana Valverde ${ }^{1,2^{*}}$
}

\begin{abstract}
Background: Pulmonary arterial hypertension $(\mathrm{PAH})$ is a rare and progressive vascular disorder characterized by increased pulmonary vascular resistance and right heart failure. The aim of this study was to analyze $5^{\prime} U T R$ region in canonical transient receptor potential isoform 6 (TRPC6) and $3^{\prime}$ UTR region in Angiotensin II type I receptor (AGTR1) genes in patients with idiopathic and associated PAH. Correlation among mutations and clinical and functional parameters was further analyzed.
\end{abstract}

Methods: Analysis of TRPC6 and AGTR1 genes was performed by polymerase chain reaction (PCR) and direct sequencing. We used a non-parametric test to determine if significant differences were found between the groups studied and chi-square test to compare clinical and hemodynamic variables among genotypes.

Results: Fifty five patients and fifty two controls were included in this study. We found statistically significant differences for $c .1-361 A>T(p=0.0077), c .1-254 C>G(p<0.0001)$ and $c .1-218 C>T(p=0.0021)$ in TRPC6 gene and c.1166A > C ( $p<0.001)$ in AGTR1 gene, between patients and controls. Idiopathic PAH patients (IPAH) and controls presented significant differences for all 3 TRPC6 polymorphisms $(p=0.020),(p=0.002)$ and $(p=0.008)$ respectively, and also showed differences for AGTR1 gene $(p<0.001)$. In associated PAH (APAH) patients we found statistical differences for $c .1-254 C>G(p<0.001)$ and $c .1-218 C>T(p=0.001)$ in TRPC6 gene and c.1166A $>C(p=0.001)$ in AGTR1 gene. Several clinical and hemodynamic parameters showed significant differences between carriers and non-carriers of these single nucleotide polymorphisms (SNPs). Nineteen patients were carriers of all 3 SNPs in TRPC6 gene and presented a more severe phenotype with differences in mean pulmonary arterial pressure $(p=0.016)$, systolic pulmonary arterial pressure $(p=0.040)$, cardiac index $(p<0.001)$ and 6 minute walking test $(p=0.049)$. 16 of these patients harbored the SNP in AGTR1 gene. These patients showed differences in age at diagnosis $(p=0.049)$, mean pulmonary arterial pressure $(p=0.033)$, cardiac index $(p=0.002)$ and 6 minute walking test $(p=0.039)$.

Conclusions: PAH is a rare disease with pulmonary vascular remodeling caused in part by a heterogeneous constellation of genetic arrangements. This study seems to suggest that C.1-361A > T, c.1-254C > G and c.1-218C > T polymorphisms in TRPC6 gene and c.1166A > C polymorphism in AGTR1 could have a role in the development of this disease.

Keywords: Pulmonary Arterial Hypertension, TRPC6, AGTR1, Polymorphism, Correlation genotype/phenotype

\footnotetext{
* Correspondence: dianaval@uvigo.es

'Department Biochemistry, Genetics and Immunology, Faculty of Biology, University of Vigo, Campus As Lagoas Marcosende S/N, 36310 Vigo, Spain ${ }^{2}$ Instituto de Investigación Biomédica de Vigo (IBIV), Vigo, Spain

Full list of author information is available at the end of the article
} 


\section{Background}

Pulmonary arterial hypertension (PAH; OMIM 178600, ORPHA 422) is a rare and progressive vascular disorder characterized by increased pulmonary vascular resistance and right heart failure. It is diagnosed when mean pulmonary arterial pressure $(\mathrm{mPaP})$ at rest is $\geq 25 \mathrm{mmHg}$ with a pulmonary arterial wedge pressure (PAWP) $\leq$ $15 \mathrm{mmHg}$ [1]. Symptoms of PAH include fatigue, shortness of breath and syncope. The estimated incidence is approximately $2-5$ cases per million per year. For adults, mean age at presentation ranges from 36 to 50 years, although individuals at any age could be affected [2]. The disease is more frequent in women, with a ratio of at least 1.7:1 [3]. Progression of pulmonary hypertension leads to right ventricular failure and death in three years from diagnosis without treatment [4]. PAH can be inherited (HPAH), idiopathic (IPAH), or associated with other diseases, drug or toxin exposures (APAH) [5]. When familial aggregation or a genetic defect has been identified in IPAH patients, they will be classified as HPAH [6]. Much of what is known about the genetic basis of PAH is related to mutations in bone morphogenetic protein receptor 2 (BMPR2) [7-9]. Patients harboring BMPR2 mutations have some differences in clinical course and outcomes [10]. However, phenotypic expression of PAH is highly variable, probably related to environmental factors, other genes and/or genetic modifiers [11-13].

In human pulmonary artery smooth muscle cells (PASMCs), the canonical transient receptor potential $(T R P C)$ channel genes are involved in agonist-mediated pulmonary vasoconstriction and mitogen-mediated cell proliferation [14]. Of the seven TRPC (TRPC1-7) isoforms identified, recently it has been demonstrated that only TRPC1, TRPC4, and TRPC6 are expressed in distal pulmonary artery smooth muscle and PASMCs $[15,16]$. TRPC6 is an important isoform highly expressed in the lungs and pulmonary arteries. TRPC6 upregulation is also a critical initial step in the increase of $\left[\mathrm{Ca}_{2}^{+}\right]_{\mathrm{cyt}}$ required for mitogen-mediated PASMC proliferation and a key contributor to the elevated $\left[\mathrm{Ca}_{2}^{+}\right]_{\mathrm{cyt}}$ in PAH PASMC $[17,18]$. The c.1-361A $>$ T (rs41302375), c.1-254C > G (rs3824934) and c.1-218C $>\mathrm{T}$ (rs56134796) polymorphisms located in $5^{\prime}$-untranslated region (UTR) may be involved in the development of PAH [19].

Angiotensin II is a potent vasopressor hormone and a primary regulator of aldosterone secretion. It is an important factor controlling blood pressure and an essential effector on the regulation of cardiovascular homeostasis. Angiotensin II type I receptor (AGTR1) plays an important role in blood pressure control and is implicated in the pathogenesis of coronary diseases [20,21]. Distal muscularization in pulmonary vessels induced by chronic hypoxia is associated with an early and transient increase in AGTR1 indicating that the vasotonic response to angiotensin II is mainly due to this receptor [22]. The c.1166A $>\mathrm{C}$ (rs5186) polymorphism in the $3^{\prime}$-UTR of the gene has been extensively studied in hypertension $[23,24]$ and has been related to later age at diagnosis in IPAH suggesting a role in the phenotypic variability of this disease [25].

The aim of this study was to analyze three SNPs located in 5'UTR region in TRPC6 gene and one SNP in 3'UTR region in AGTR1 gene, in consecutive patients with IPAH and APAH, and to search for associations with clinical and hemodynamic variables.

\section{Methods}

\section{Patients and samples}

Patients with idiopathic or associated PAH (group 1 of the new classification of Nice) [5] followed in our PAH Unit were included in this study. Cardiac catheterization was performed using the latest consensus diagnostic criteria of the ERS-ESC (mean resting pulmonary pressure $\geq 25 \mathrm{mmHg}$, PAWP $<15 \mathrm{mmHg}$ ) in all cases [26]. PAH was considered idiopathic after exclusion of any of the possible clinical causes associated with the disease. Clinical history included use of drugs, especially appetite suppressants, and screening for connective tissue and hepatic diseases. The study included serology for HIV, autoimmunity, thoracic CT scan and echocardiography. Patients with chronic lung disease that could be related to $\mathrm{PAH}$, were excluded. Fifty two healthy individuals were used as controls. All patients and controls signed an informed consent. The Autonomic Ethics Committee approved the study (Comité Autonómico de Ética da Investigación de Galicia - CAEI de Galicia).

\section{Identification of SNPs in TRPC6 and AGTR1 genes}

Genomic DNA was extracted from leukocytes isolated from venous blood using the FlexiGene DNA Kit (Qiagen, Germany) according to the manufacturer's protocol. We performed a PCR with $0.2 \mathrm{U}$ of Taq Polymerase (Biotaq, Bioline, UK) and $0.75 \mathrm{mM} \mathrm{Cl}_{2} \mathrm{Mg}$ for the c.1-361A > T, c.1-254C > G and c.1-218C > T polymorphisms in TRPC6 gene and c.1166 A $>$ C polymorphism in AGTR1 gene. Amplification conditions were as follows: $95^{\circ} \mathrm{C}$ for $5 \mathrm{~min}, 35$ cycles of $95^{\circ} \mathrm{C}$ for $1 \mathrm{~min}, 60^{\circ} \mathrm{C}$ for $1 \mathrm{~min}, 72^{\circ} \mathrm{C}$ for $1 \mathrm{~min}$ and finally, $72^{\circ} \mathrm{C}$ for $10 \mathrm{~min}$ for TRPC6 gene and $95^{\circ} \mathrm{C}$ for $5 \mathrm{~min}, 35$ cycles of $95^{\circ} \mathrm{C}$ for $30 \mathrm{~s}, 58^{\circ} \mathrm{C}$ for $30 \mathrm{~s}, 72^{\circ} \mathrm{C}$ for $30 \mathrm{~s}$ and finally, $72^{\circ} \mathrm{C}$ for $7 \mathrm{~min}$ for AGTR1 gene. The forward and reverse primers were $5^{\prime}$-AGAAAGAAGAGGCTCGTGTCC-3' and 5' $^{\prime}$ GAAAAGTCACCACTTAAGGGGG-3', described by Yu Y et al. [19], and 5'-AGAAGCCTGCACCATGTTTT-3' and 5'-TGTGGCTTTGCTTTGTCTTG-3', described by Jira $\mathrm{M}$ et al. [27], for the TRPC6 and AGTR1 genes, respectively. 
PCR products were separated by electrophoresis through 3\% agarose with ethidium bromide staining. The electrophoresis product was purified using the Nucleic Acid and Protein Purification (NucleoSpin Extract II) kit by Macherey-Nagel (Germany). PCR products were sequenced with the BigDye Terminator version 3.1 Cycle Sequencing Kit by Applied Biosystems (USA) and the reactions were performed on GeneAmp PCR System 2700 by Applied Biosystems (USA). The sequencing reactions were precipitated and finally analyzed on an ABI PRISM 3100 genetic analyzer (Applied Biosystems, USA).

Sequence data was aligned to reference Ensembl DNA sequence [ENSG00000137672], for TRPC6 gene, and [ENSG00000144891], for AGTR1 gene, and examined for sequence variations. Detected polymorphisms were confirmed by a second independent PCR reaction and were identified in both forward and reverse strands.

\section{Statistical analysis}

Values are expressed as mean \pm SD (standard deviation). Non-parametric test were used to determine if there were significant differences between groups (patients with $\mathrm{PAH}$ and controls). Chi-square test was used to compare clinical and hemodynamic variables among genotypes (variables were categorized according to the best cut off point by ROC curve). These correlations were analyzed by the Spearman test. Probability values less than 0.05 were considered statistically significant. Statistical analyses were performed using SPSS for Windows (v19.0).

\section{Results}

Description of the cohort

Fifty five unrelated PAH patients (28 idiopathic, 18 associated to connective tissue disease, 4 related to HIV and 5 porto-pulmonary hypertension) and 52 healthy controls without familial history of $\mathrm{PAH}$ were included (Figure 1). At the time of diagnosis 7 patients were in functional class (FC) I, 19 patients in FC II, 25 patients in FC III and 4 in FC IV. Clinical features of patients are shown in Table 1.

\section{Analysis of SNPs in the 5'UTR region of TRPC6 gene}

We found statistically significant differences between patients and controls $(p=0.0077)$ for TRPC6 c.1-361A $>\mathrm{T}$ polymorphism (Figure 2). TT genotype was present in 2 patients $(3.7 \%)$ but in any control; AT genotype was also more frequent in patients (52\%) than controls (31\%), whose most common genotype was AA. These results are shown in Figure 3a. Patients showed an allele frequency of 0.690 for $\mathrm{A}$ and 0.303 for $\mathrm{T}$, but this frequency was 0.836 for $\mathrm{A}$ and 0.163 for $\mathrm{T}$ in controls. Patients with this polymorphism were not in Hardy-Weinberg Equilibrium (H-WE) with $\mathrm{p}=0.0085$ but controls were in $\mathrm{H}-\mathrm{WE}$ with $\mathrm{p}=0.1588$. The predominant genotype for IPAH patients was AT (61\%) and for APAH patients was AA (50\%) (Figure 4a). Comparing the distribution of this polymorphism, in healthy people reached statistically differences with IPAH $(p=0.02)$, but not with APAH $(p=0.097)$.

The most common genotype in patients for c.1-254C > G polymorphism (Figure 2) was CG (63.7\%), while in

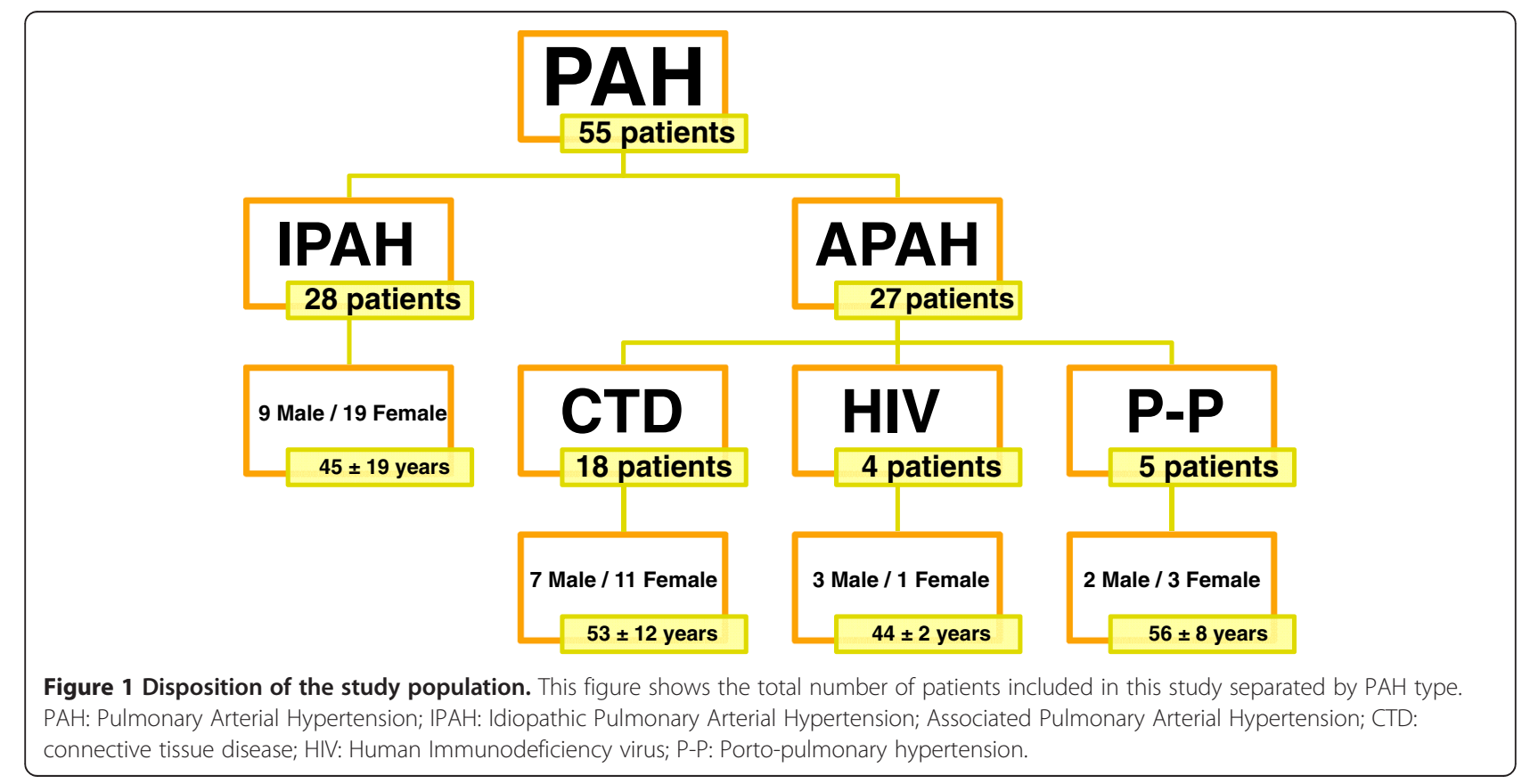


Table 1 Clinical features and hemodynamic parameters of patients

\begin{tabular}{|c|c|}
\hline Clinical features and hemodynamic parameters & Clinical data \\
\hline Number & 55 \\
\hline Age at diagnosis (years) & $49 \pm 16$ \\
\hline Gender & $34 \mathrm{~F} / 21 \mathrm{M}$ \\
\hline$m P a P(m m H g)$ & $48 \pm 14$ \\
\hline sPaP $(\mathrm{mmHg})$ & $69 \pm 19$ \\
\hline Pulmonary vascular resistance $\left(\mathrm{mmHg} \cdot \Gamma^{-1} \cdot \mathrm{m}^{-1}\right)$ & $8.3 \pm 3.3$ \\
\hline Cardiac index $\left(I \cdot m^{-1} \cdot m^{-2}\right)$ & $2.9 \pm 0.7$ \\
\hline $6 M W T(m)$ & $415 \pm 146$ \\
\hline
\end{tabular}

Values are expressed as mean \pm standard deviation; F: female, $\mathrm{M}$ : male; $\mathrm{mPaP}$ : mean pulmonary pressure; sPaP: systolic pulmonary pressure; $6 \mathrm{MWT}$ : 6 minute walking test.

controls was CC (75\%). GG genotype was seen in only 2 patients but not in controls. We found high statistically significant differences between patients and controls for this polymorphism $(p<0.0001)$. Besides, this SNP presented statistical differences between IPAH and controls $(\mathrm{p}=0.002)$ and APAH and controls $(\mathrm{p}<0.0001)$. These results are shown in Figure $3 \mathrm{~b}$. Patients were not in
$\mathrm{H}-\mathrm{WE}$ in contrast to controls $(\mathrm{p}=0.0037$ and $\mathrm{p}=0.3029$, respectively). The allele frequency for $\mathrm{C}$ was 0.645 in patients and 0.875 in controls and for $\mathrm{G}$ was 0.354 in patients and 0.125 in controls. For IPAH and APAH patients the most common genotype was GC (64.2\% and $60 \%$, respectively) (Figure $4 b$ ).

Results for c.1-218C > T polymorphism (Figure 2) are summarized in Figure 3c. For patients, the most common genotype was CT (52.8\%), while in controls was CC (73\%). TT genotype was seen in 3 patients $(5.5 \%)$ and any controls. The distribution of this polymorphism reached significant differences between patients and controls $(p=0.0021)$ and between IPAH (most common CT, 57.2\%) and APAH (most common CC, 44.5\%) (Figure 4c). Both IPAH and APAH patients showed statistical differences with controls $(p=0.008$ and $p=0.014$, respectively). Allele frequency for $\mathrm{A}$ was 0.609 in patients and 0.836 in controls and for C, 0.390 and 0.163 in patients and controls respectively. Besides, patients $(p=0.0538)$ and controls $(p=0.6034)$ were in H-WE.

In this study, 20 of the 55 patients were carriers of the 3 polymorphisms in TRPC6 gene (36.4\%), 11 IPAH (39.2\%) and 9 APAH (30\%).

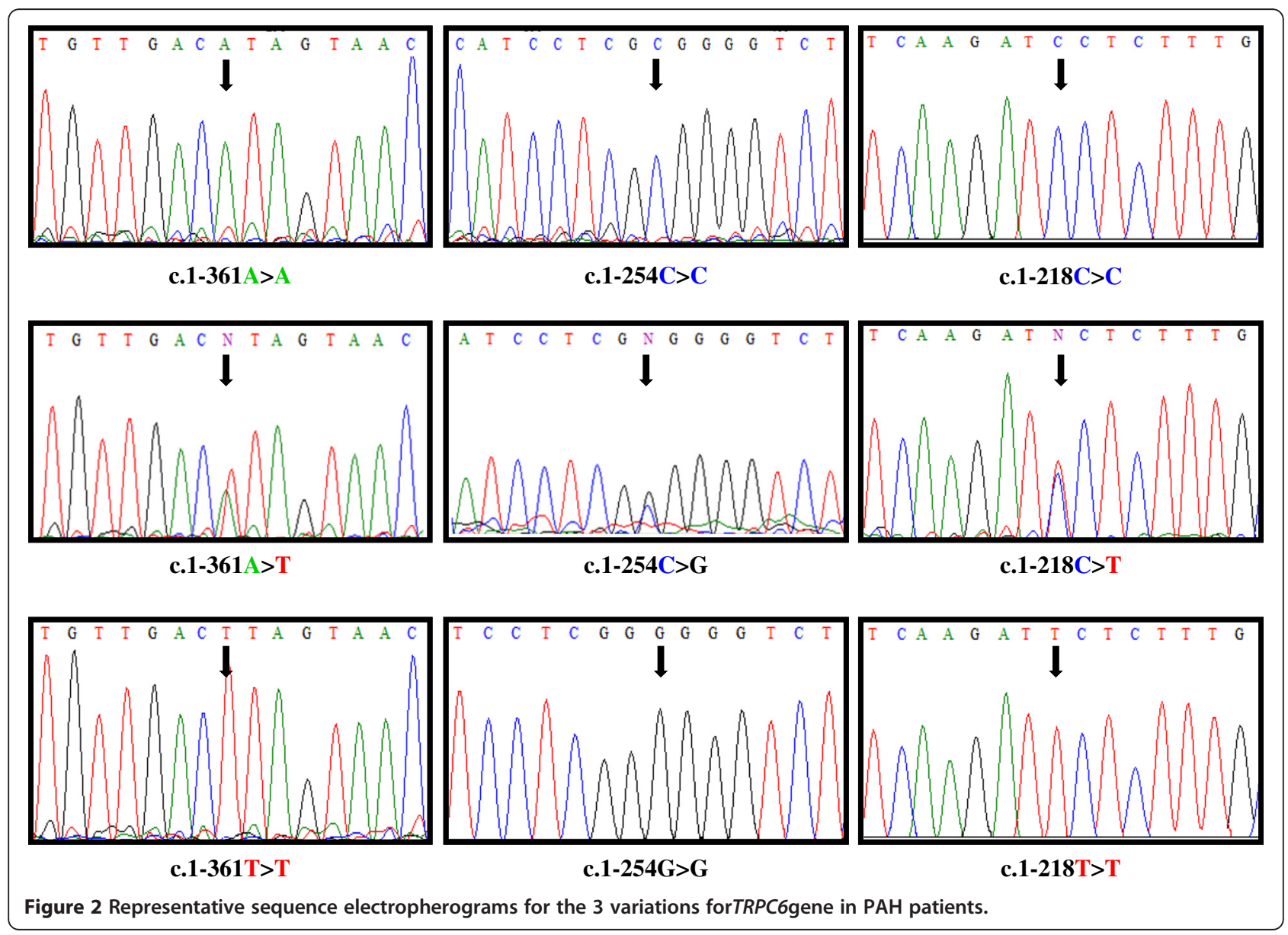



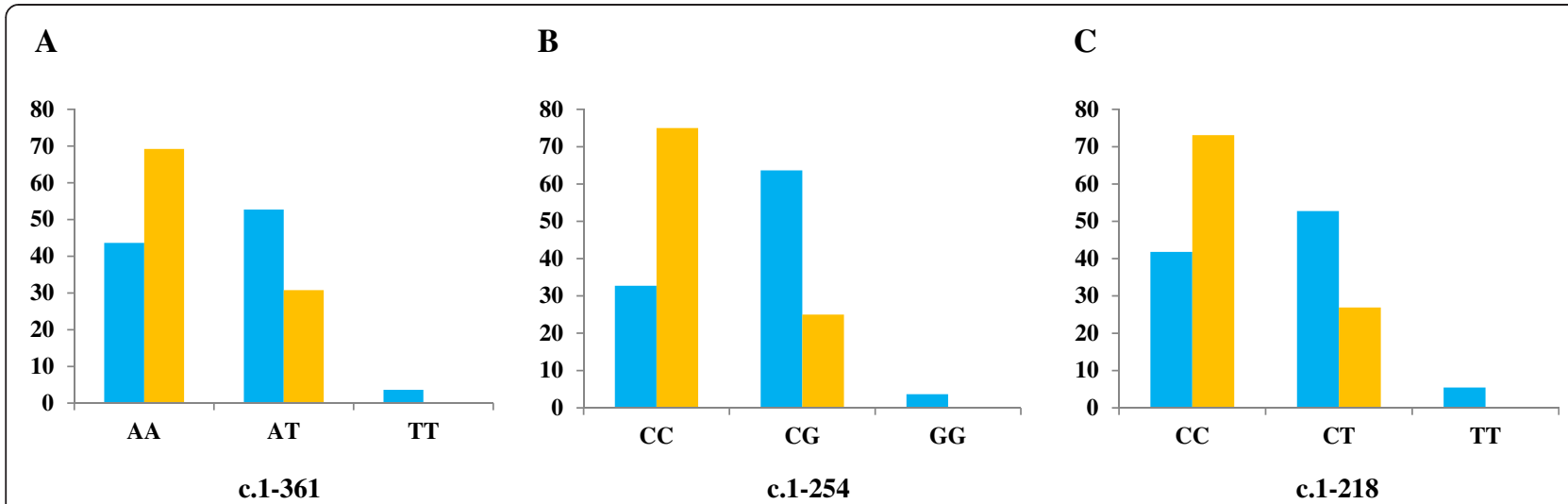

Figure 3 Genetic disposition between PAH patients (blue) and controls (orange) for eachTRPC6SNPs. A: C.1-361; B: C.1-254; C: C.1-218.

Analysis of the SNP in AGTR1 gene 3'UTR region

We obtained statistically significant differences for c.1166A > C polymorphism (Figure 5), located on 3'UTR of AGTR1 gene, between patients and controls ( $\mathrm{p}>$ $0.0001)$. This SNP was seen in patients with a frequency of $60 \%$ in heterozygosis (AC) and $9 \%$ in homozygosis (Figure 6a). AC/CC genotype was found in $72.4 \%$ of IPAH, and $68 \%$ of APAH but only in $25 \%$ of healthy people. These two groups (IPAH vs APAH) showed almost no difference between genotypes for this polymorphism (Figure 6b). Both IPAH $(p>0.0001)$ and APAH patients $(p=0.001)$ showed statistical differences with controls. Allele frequency for A was 0.609 in patients and 0.807 in controls, however was 0.391 for $C$ in patients and 0.193 in controls. For this change patients were not in H-WE with $\mathrm{p}=0.0063$ in contrast to controls with $\mathrm{p}=0.1445$.

\section{Correlation with clinical features and hemodynamic parameters}

We compared clinical features and hemodynamic parameters between patients according to these SNPs. The variables included were: gender, age at diagnosis, mean pulmonary artery pressure $(\mathrm{mPaP})$, systolic pulmonary artery pressure $(\mathrm{sPaP})$, pulmonary vascular resistance (PVR), cardiac index $(\mathrm{CI}), 6$ minute walking test $(6 \mathrm{MWT})$ and type of PAH (IPAH vs APAH). Variables were categorized according to the best cut off point by ROC curve.

Regarding to genotype, several clinical and hemodynamics parameters showed statistically significant differences. For TRPC6 c.1-361A $>\mathrm{T}$ polymorphism and gender $(\mathrm{p}=0.002)$, AT genotype was more frequent in males (78\%) and AA genotype in females (56.2\%), and patients with AT genotype presented lower CI ( $\mathrm{p}=0.005)$. For c.1-254C > G polymorphism we only found statistically differences for CI $(\mathrm{p}=0.016)$, with lower values in carriers of this SNP. For c.1-218C > T polymorphism we also found statistically significant differences in gender $(\mathrm{p}=0.016)$, with $\mathrm{CT}$ as predominant genotype in males (65\%) and CC females (47\%). There were also differences in $\mathrm{sPaP}(\mathrm{p}=0.039)$, PVR $(\mathrm{p}=0.027)$ and CI $(\mathrm{p}<0.001)$. Patients carrying this polymorphism had higher values of sPaP and PVR and lower CI (Table 2).

For c.1166A > C polymorphism in AGTR1 gene, carriers showed significant higher values for $\mathrm{mPaP}(\mathrm{p}=0.035)$ and

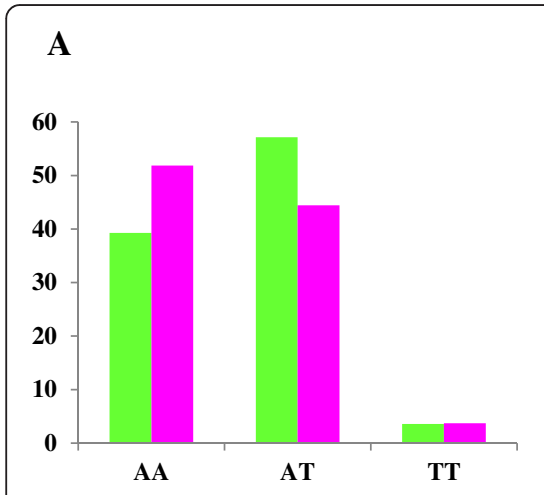

c.1-361

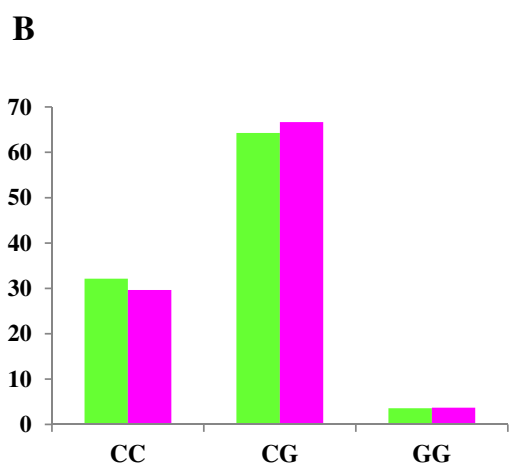

c.1-254

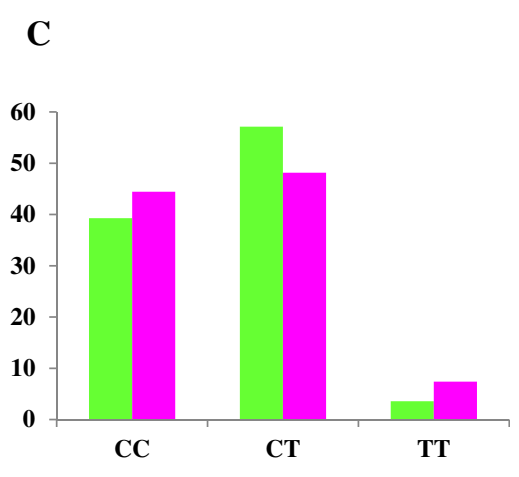

c.1-218

Figure 4 Genetic disposition of the IPAH (green) and APAH (pink) population forTRPC6gene. A: c.1-361; B: c.1-254; C: c.1-218. 


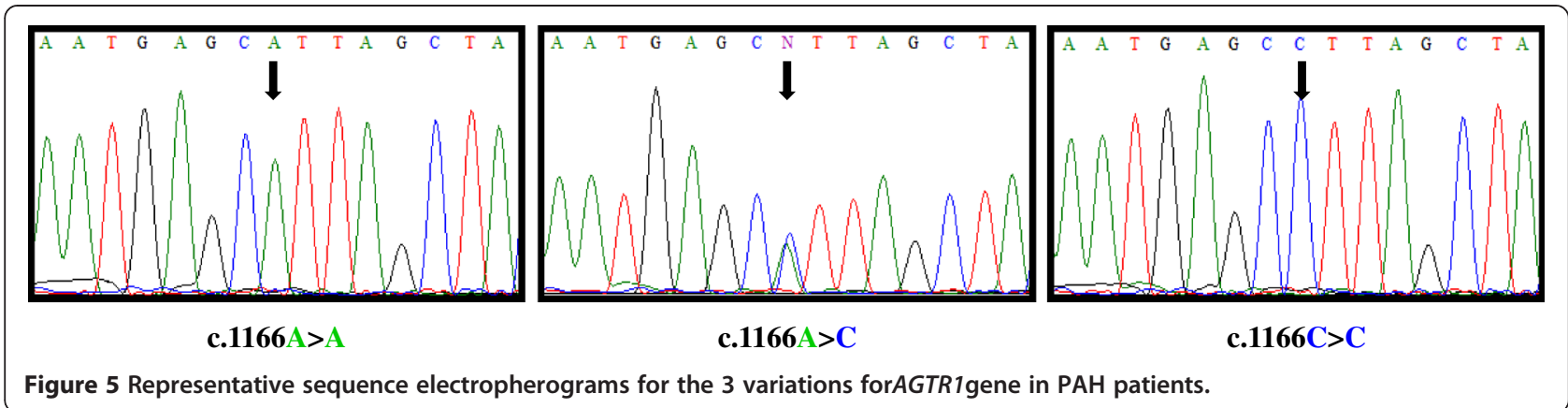

$\operatorname{PVR}(\mathrm{p}=0.035)$ and lower for CI $(\mathrm{p}=0.034)$ (Table 3$)$. Clinical and hemodynamic parameters did not show any significant differences between associated and idiopathic PAH.

Patients carrying all 3 polymorphisms showed statistically significant differences in gender $(\mathrm{p}=0.016), \mathrm{mPaP}$ (0.011), $\mathrm{sPaP}(\mathrm{p}=0.040), \mathrm{CI}(\mathrm{p}<0.001)$ and 6MWT (0.049). The combination of these polymorphisms was more frequent in males (59\%) than females (41\%), with higher values of $\mathrm{mPaP}, \mathrm{sPaP}$ and PVR, and lower values of CI and 6MWT (Table 4).

The combination of all SNPs in TRPC6 gene and AGTR1 gene was detected in $27 \%$ of patients analyzed in this study. These patients had a significantly earlier age at diagnosis compared to patients without any SNPs $(\mathrm{p}=0.049)$. Furthermore, these patients showed a higher value of $\mathrm{mPaP}(\mathrm{p}=0.033)$ and a lower value for $\mathrm{CI}$ $(\mathrm{p}=0.002)$ and 6MWT $(\mathrm{p}=0.039)$. These results are summarized in Table 4.

The mean follow-up period was 14 months. Three patients died during this time (2 APAH, $1 \mathrm{IPAH})$, therefore it was not possible to analyze mortality. The patient with idiopathic PAH presented the 3 SNPs in TRPC6 gene and the SNP in AGTR1 gene. For the two APAH patients, one was a carrier of all 3 SNPs in TRPC6 gene, and the other patient had c.1-361A $>\mathrm{T}$ polymorphism in TRPC6 gene and the SNP in AGTR1 gene.

\section{Discussion}

The aim of this study was to analyze three polymorphisms in the 5'UTR region of TRPC6 gene and another polymorphism in the 3'UTR region of AGTR1 gene and correlate them with clinical features trying to finding out if they modulate the phenotype of PAH patients. We found statistically significant differences between patients and controls in hemodynamic parameters for these SNPs.

TRPCs play an important role in the cardiovascular system [28]. TRPC6 is known to be involved in forming receptor-operated $\mathrm{Ca}^{2+}$ channels andTRPC6 protein is expressed in lung, brain and smooth muscle cells [29]. In PASMC this protein takes part of the functional $\mathrm{Ca}^{2+}$ channels that are activated by vasoconstrictor and mitogenic factors. Enhanced $\mathrm{Ca}^{2+}$ influx and elevated $\left[\mathrm{Ca}^{2+}\right]$ cyt are requisites for normal PASMC growth, whereas an excessive $\mathrm{Ca}^{2+}$ intake and the subsequent sustained increase in $\left[\mathrm{Ca}^{2+}\right]_{\text {cyt }}$ may be critical stimuli for IPAHPASMC overgrowth [30]. Even in cardiac myocytes, overexpressed TRPC6 plays an important role in
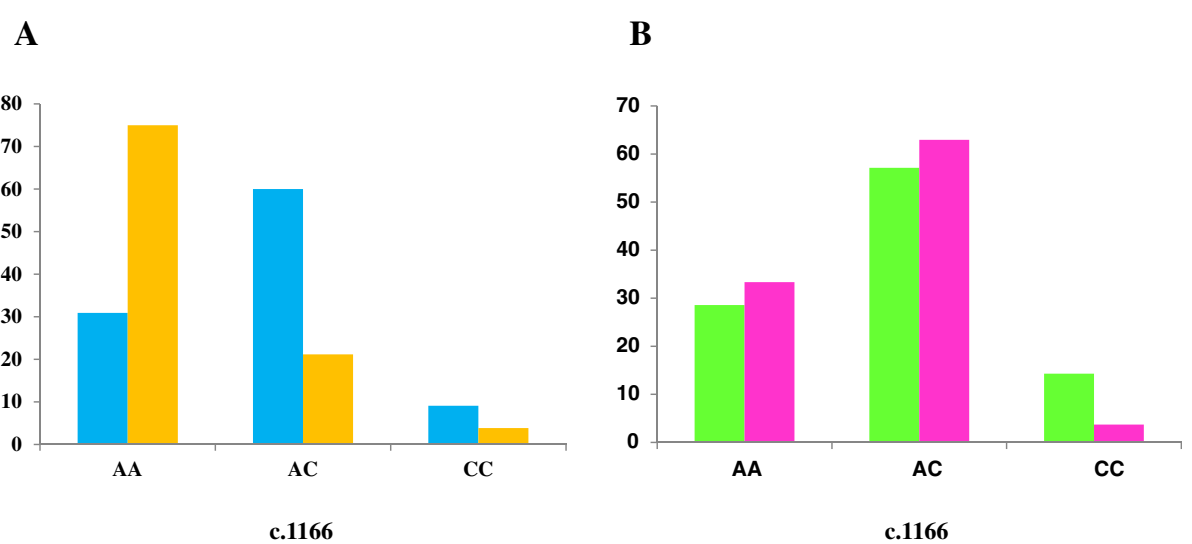

Figure 6 Genetic disposition of the study population inAGTR1SNP. A: Show the differences between patients (blue) and controls (orange). B: Show the differences between IPAH patients (green) and APAH patients (pink). 
Table 2 Clinical features and hemodynamic parameters of patients with each TPRC6 polymorphism

\begin{tabular}{|c|c|c|c|c|c|c|}
\hline \multirow{2}{*}{$\begin{array}{l}\text { Clinical features and } \\
\text { hemodynamic } \\
\text { parameters }\end{array}$} & \multicolumn{2}{|c|}{ Carriers of c.1-361A $>$ T mutation } & \multicolumn{2}{|c|}{ Carriers of c.1-254C > G mutation } & \multicolumn{2}{|c|}{ Carriers of $\mathrm{c} .1-218 \mathrm{C}>\mathrm{T}$ mutation } \\
\hline & Clinical data & p-value & Clinical data & p-value & Clinical data & p-value \\
\hline Number & 32 & & 37 & & 32 & \\
\hline Gender & $25 \mathrm{~F} / 7 \mathrm{M}$ & 0.002 & $23 \mathrm{~F} / 14 \mathrm{M}$ & 0.177 & $11 \mathrm{~F} / 21 \mathrm{M}$ & 0.035 \\
\hline Age at diagnosis (years) & $50 \pm 16$ & 0.392 & $48 \pm 16$ & 0.403 & $52 \pm 17$ & 0.673 \\
\hline $\mathrm{mPaP}(\mathrm{mmHg})$ & $50 \pm 14$ & 0.161 & $48 \pm 14$ & 0.162 & $48 \pm 15$ & 0.307 \\
\hline$s \mathrm{PaP}(\mathrm{mmHg})$ & $71 \pm 19$ & 0.190 & $68 \pm 18$ & 0.195 & $70 \pm 20$ & 0.039 \\
\hline PVR $\left(m m H g . I^{-1} \cdot m^{-1}\right)$ & $7.8 \pm 2.3$ & 0.336 & $7.6 \pm 2.6$ & 0.292 & $8 \pm 2.8$ & 0.027 \\
\hline$C I\left(I \cdot m^{-1} \cdot m^{-2}\right)$ & $2.6 \pm 0.7$ & 0.005 & $2.6 \pm 0.6$ & 0.016 & $2.6 \pm 0.7$ & 0.000 \\
\hline $6 M W T(m)$ & $400 \pm 160$ & 0.136 & $423 \pm 152$ & 0.332 & $395 \pm 141$ & 0.168 \\
\hline
\end{tabular}

forming $\mathrm{Ca}^{2+}$ dependent calcineurin [28]. Downregulation of TRPC6 inhibits PASMC proliferation [31].

$\mathrm{Yu} \mathrm{Y}$ et al. [19] studied the promoter region of this gene and found that only TRPC6 c.1-254C > G polymorphism was related to IPAH patients. However, in our study, we found that TRPC6 c.1-361A > T, c.1-254C > G and c.1-218C $>\mathrm{T}$ polymorphisms had different genotype frequency in patients and healthy people, showing significant differences between groups. This could be due to the small sample size more than ethnical differences, since our patient's cohort has a European background and the allele frequencies described in the control groups are quite similar in the two studies. The study of Yu Y et al. showed that allele $G$ in $1-254 C>G$ polymorphism could be responsible for the abnormal TRPC6 expression and function. The $\mathrm{C}>\mathrm{G}$ conversion in $\mathrm{PAH}$ may alter the regulation of cell cycle progression and proliferation increasing the $\left[\mathrm{Ca}^{2+}\right]_{\text {cyt. }}$ This channel influx through TRPCs is known to contribute to proliferative mechanisms in PASMC. This SNP showed statistically differences for CI between our patients and controls. Patients carrying the $\mathrm{G}$ allele have a lower value, indicating a more severe disease than non-carriers. Perhaps, as Yu Y et al. suggest, TRPC6 c.1-254C > G SNP may predispose individuals to an increased risk of IPAH by linking abnormal TRPC6

Table 3 Clinical features and hemodynamic parameters in patients with c.1166A > C change

\begin{tabular}{|c|c|c|}
\hline \multirow{2}{*}{$\begin{array}{l}\text { Clinical features and } \\
\text { hemodynamic } \\
\text { parameters }\end{array}$} & \multicolumn{2}{|c|}{ Carriers of c. $1166 \mathrm{~A}>\mathrm{C}$ mutation } \\
\hline & Clinical data & p-value \\
\hline Number & 38 & \\
\hline Gender & $\mathrm{F} / 7 \mathrm{M}$ & 0.511 \\
\hline Age at diagnosis (years) & $49 \pm 16$ & 0.265 \\
\hline$m P a P(m m H g)$ & $46 \pm 13$ & 0.035 \\
\hline$s P a P(m m H g)$ & $69 \pm 18$ & 0.207 \\
\hline $\operatorname{PVR}\left(m m H g . \Gamma^{-1} \cdot m^{-1}\right)$ & $7.9 \pm 2.8$ & 0.035 \\
\hline$C l\left(I . m^{-1} \cdot m^{-2}\right)$ & $2.4 \pm 0.7$ & 0.034 \\
\hline $6 M W T(m)$ & $413 \pm 145$ & 0.138 \\
\hline
\end{tabular}

transcription to nuclear factor- $\kappa \mathrm{B}(\mathrm{NF} \kappa \mathrm{B})$. This fact could be more important for patients with APAH which bear a significant inflammatory burden, as those related to connective tissue diseases, HIV and schistosomiasis, [32]. However, we did not find any differences between IPAH and APAH in our patients.

Regarding to genotype-phenotype correlation, c.1-361A > T polymorphism showed differences in gender, being $\mathrm{T}$ allele more frequent in males. We also found a significantly lower CI value in these patients. This data may indicate that this change could have some role in the development of this disease. Similar to c.1-361A > T, c.1-218C $>\mathrm{T}$ polymorphism showed significant differences in gender, being more frequent in males, with low CI and higher sPaP and PVR. Carriers of this polymorphism seem to have a more severe disease.

It has been reported that PASMC from patients with IPAH are hyperproliferative, with markedly increased expression of TRPC6 [28]. PASMC proliferation is regulated by intracellular $\mathrm{Ca}^{2+}$. Elevated $\left[\mathrm{Ca}^{2+}\right]_{\mathrm{cyt}}$ may induce PASMC proliferation by initiating and promoting the cell cycle, and by triggering or promoting gene transcription via phosphorylation of transcription factors.

For the 254 allele a new binding site for $\mathrm{NF}_{\kappa} \mathrm{B}$ was created, promoting not also $\mathrm{NFKB}-$ mediated TRPC6 transcription, but perhaps enhancing basal transcription of TRPC6 in PASMCs [29]. The c.1-254C $>\mathrm{G}$ functional study revealed that this SNP enhances $N F \kappa B$ mediated promoter activity and stimulate TRPC6 expression in PASMCs. Inhibition of NFKB activity attenuated TRPC6 expression and decreased agonist activated $\mathrm{Ca}^{2+}$ influx in PASMCs of IPAH patients harboring the c.1-254G allele [32].Others SNPs in this region could facilitate interactions of several transcription factors (nuclear factor of activated T-cells (NFAT) and Activation Protein-1 (AP-1)) increasing TRPC6 transcription. Related to it, patients with $\mathrm{PAH}$ carrying these polymorphisms could have a worse prognosis than non-carriers. The enhanced transcriptional regulation of TRPC6 and augmented function of TRPC6 channels resulting from these 
Table 4 Clinical features and hemodynamic parameters in patients harboring the 3 SNPs ofTRPC6gene and patients with these SNPs plusAGTR1SNP

\begin{tabular}{|c|c|c|c|c|}
\hline \multirow{2}{*}{$\begin{array}{l}\text { Clinical features and } \\
\text { hemodynamic } \\
\text { parameters }\end{array}$} & \multicolumn{2}{|c|}{$\begin{array}{l}\text { Carriers of c.1-361A }>\mathrm{T}, \mathrm{c} .1-254 \mathrm{C}>\mathrm{G} \\
\text { and } \mathrm{c} .1-218 \mathrm{C}>\mathrm{T} \text { mutations }\end{array}$} & \multicolumn{2}{|c|}{$\begin{array}{l}\text { Carriers of c.1-361A }>T, c .1-254 C>G, c .1-218 C>T \\
\text { and c. } 1166 A>C \text { mutations }\end{array}$} \\
\hline & Clinical data & p-value & Clinical data & $p$-value \\
\hline Number & 19 & & 16 & \\
\hline Gender & $7 \mathrm{~F} / 12 \mathrm{M}$ & 0.016 & $7 \mathrm{~F} / 9 \mathrm{M}$ & 0.135 \\
\hline Age at diagnosis (years) & $51 \pm 17$ & 0.348 & $53 \pm 17$ & 0.049 \\
\hline$m P a P(m m H g)$ & $51 \pm 14$ & 0.011 & $52 \pm 16$ & 0.033 \\
\hline$s P a P(m m H g)$ & $69 \pm 20$ & 0.040 & $68 \pm 22$ & 0.222 \\
\hline PVR $\left(m m H g . I^{-1} \cdot m^{-1}\right)$ & $7.4 \pm 2.6$ & 0.576 & $7.2 \pm 2.9$ & 0.533 \\
\hline$C I\left(I . m^{-1} \cdot m^{-2}\right)$ & $2.5 \pm 0.7$ & 0.000 & $2.7 \pm 0.8$ & 0.002 \\
\hline $6 M W T(m)$ & $363 \pm 159$ & 0.049 & $343 \pm 165$ & 0.039 \\
\hline
\end{tabular}

polymorphisms may predispose to an increased risk of developing PAH.

Patients with all 3 SNPs in TRPC6 gene showed statistically significant differences in gender, $\mathrm{mPaP}, \mathrm{sPaP}, \mathrm{CI}$ and $6 \mathrm{MWT}$. Being a carrier of the three polymorphisms was more common in men than in women, even after each SNP was evaluated separately. These patients have higher values of $\mathrm{mPaP}, \mathrm{sPaP}$ and PVR, and lower values of $\mathrm{CI}$ and 6MWT. It seems that carriers of the 3 polymorphisms of TRPC6 gene present a more severe disease. Although we did not find statistically significant differences in age of diagnosis in our patients, it would be of great interest to know if these 3 SNPs together are related to an earlier onset of the disease.

$\mathrm{PAH}$ is more common in women than in men. However, TRPC6 gene polymorphisms appear more frequently in men. Patients with one or more of these polymorphisms probably are more likely to develop the disease, meaning that this gene could play a more specific role in males. Boney-Montoya et al. [33] demonstrated that TRPC6 expression is not regulated by estradiol in human breast adenocarcinoma cell line (MCF-7) cells, but the pathway of TRPC6 is still not well understood and perhaps others factors could influence the expression of this channel.

c.1166A > C polymorphism in AGTR1 gene is a variant extensively investigated in systemic hypertension, but to date only one article has shown a possible role in pulmonary hypertension [25], finding a relation between AGTR1 polymorphism and age at diagnosis, something that could not be demonstrated in our study. We observed significant differences for this polymorphism between patients and controls. There is enough evidence demonstrating that the binding of angiotensin II to AGTR1 exerts a pivotal effect on the regulation of vascular tone and saltwater homeostasis. In our cohort the genotype $\mathrm{CC}+\mathrm{CA}$ was present in $69 \%$ of patients and only $25 \%$ of healthy. The presence of $\mathrm{C}$ allele has been associated with hypertension, aortic stiffness, left ventricular mass and greater coronary artery vasoconstriction [34]. The CC + CA genotypes were associated with a more advanced disease and a significantly higher mortality compared with AA genotype. For AGTR1 gene,, its potential role in the development of pulmonary hypertension is not well understood, although its function is known from almost 30 years. Li Y et al. found that the relation of c.1166A > C polymorphism with coronary heart disease was stronger in older than younger subjects [23]. We detected differences between patients with this SNP for $\mathrm{mPaP}, \mathrm{PVR}$ and CI. In our series, patients harboring this SNP had a more severe phenotype.

Functional studies have shown that c.1166A $>\mathrm{C}$ polymorphism is located in a cis-regulatory site recognized by specific microRNA (miRNA) miR-155 [35,36] which is base-pairing complementary with the 1166A allele but not with the mutant $1166 \mathrm{C}$ allele. Jirá $\mathrm{M}$ et al. described a decrease ability of miR-155 to interact with the cis-regulatory site when this allele is present [27]. Thus, the possibility of failure in the receptor as the biological base is quite likely.

It has been shown that upregulated expression of TRPM7 (transient receptor potential cation channel, subfamily $\mathrm{M}$, member 7), TRPV4 (transient receptor potential cation channel, subfamily $V$, member 4) and TRPC6 channels in PASMC from IPAH patients seems to be, at least in part, the cause for the enhanced increase in $\left[\mathrm{Ca}^{2+}\right]_{\mathrm{cyt}}$ induced by mechanical stimuli (e.g., flow shear stress and stretch). The increase of $\left[\mathrm{Ca}^{2+}\right]_{\mathrm{cyt}}$ in PASMC from IPAH patients would contribute to increased pulmonary vascular myogenic tone, sustained pulmonary vasoconstriction and pulmonary vascular medial hypertrophy. Pharmacological blockade of TRPM7, TRPV4 and TRPC6 channels and/or silent RNA (siRNA) driven downregulation of this channel expression may be a novel therapeutic approach for IPAH patients [37]. In the near future genetic information as this could guide treatment of $\mathrm{PAH}$ in a more personalized way.

Obviously, the main limitation for drawing conclusions in our study is the small number of patients, although 
the low incidence of PAH and some cases that did not consent to be included, did not allow us to have a larger series. The comprehensive study carried out, complete follow-up of all cases and the strength of some findings add value to our results.

\section{Conclusions}

$\mathrm{PAH}$ is a rare disease with pulmonary vascular remodeling caused in part by a heterogeneous constellation of genetic arrangements, which ultimately give rise to a common pathologic event, PASMC and endothelial overgrowth. Therefore, the causal and pathogenic mechanism of $\mathrm{PAH}$ may involve abnormalities in multiple genes and gene products.

This study, as well as some others previously repported, seems to suggest that c.1-361A $>$ T, c.1-254C $>$ G and c.1$218 \mathrm{C}>\mathrm{T}$ polymorphisms in TRPC6 gene and c.1166A $>\mathrm{C}$ polymorphism in AGTR1 could have an important role in the development of this disease and, perhaps, a more severe clinical course.

\begin{abstract}
Abbreviations
6MWT: 6 minute walking test; AGTR1: Angiotensin II type I receptor gene; AP-1: Activation Protein; APAH: Associated pulmonary arterial hypertension; BMPR2: Bone morphogenetics protein receptor type 2 gene; Cl: Cardiac index; CTD: Connective tissue disease; DNA: Deoxyribonucleic acid; ERS-ESC: European Respiratory Society-European Society of Cardiology; FC: Funcional class; HIV: Human Immunodeficiency virus; HPAH: Inherited pulmonary arterial hypertension; H-WE: Hardy-Weinberg Equilibrium; IPAH: Idiopathic pulmonary arterial hypertension; MCF-7: Human breast adenocarcinoma cell line; miRNA: microRNA; mPaP: Mean pulmonary arterial pressure; NFAT: Nuclear factor of activated T-cells; NFkB: Nuclear factor-kB; PAH: Pulmonary arterial hypertension; PASMC: pulmonary arteriolar smooth muscle cells; PCR: Polymerase chain reaction; PCWP: Pulmonary capillary wedge pressure; P-P: Porto-Pulmonary hypertension; PVR: Pulmonary vascular resistence; SD: Standard deviation; siRNA: Silent RNA; SNP: Single nucleotide polymorphism; sPaP: Systolic pulmonary pressure; TRPC6: Canonical transient receptor potential channel isoform 6 gene; TRPM7: Transient receptor potential cation channel, subfamily M, member 7 gene; TRPV4: Transient receptor potential cation channel, subfamily $V$, member 4 gene; UTR: Untranslated region.
\end{abstract}

\section{Competing interests}

The authors declare that they have no competing interests.

\section{Authors' contributions}

GP conceived of the study and its design, performed genetic research, data statistical analysis and interpretation, correlation genotype/phenotype and draft the manuscript. AB conceived the study, realized the collection of patients and data, statistical analysis and drafts the manuscript. DV conceived the study and participated in its design and coordination, helped to experiments and draft the manuscript. All authors read and approved the final manuscript.

\section{Acknowledgements}

We are grateful to the patients who participated in our research, we thank the physicians who participated in the collection of patients and data (Carlos Vilariño Pombo, José Manuel Cifrián, Olalla Añón) and, finally, we acknowledge the collaboration of Asociación Española de Hipertensión Pulmonar. Programa de Apoyo a las Capacidades Biomédicas (BIOCAPS) FP7-REGPOT316265.

\section{Funding}

This study was supported by the grants IN-202-05 from SOGAPAR, CO-0085-10 from Actelion Pharmaceuticals and INBIOMED 2009-063 Xunta de Galicia.

\section{Author details}

'Department Biochemistry, Genetics and Immunology, Faculty of Biology, University of Vigo, Campus As Lagoas Marcosende S/N, 36310 Vigo, Spain. ${ }^{2}$ Instituto de Investigación Biomédica de Vigo (IBIV), Vigo, Spain. ${ }^{3}$ Complexo Hospitalario Universitario de Pontevedra, Servicio de Neumología, Pontevedra, Spain.

Received: 8 October 2014 Accepted: 17 December 2014 Published online: 21 January 2015

\section{References}

1. Hoeper MM, Bogaard HJ, Condliffe R, Frantz R, Khanna D, Kurzyna M, et al. Definitions and diagnosis of pulmonary hypertension. J Am Coll Cardiol. 2013;62:25S

2. Peacock AJ, Murphy NF, McMurray JJV, Caballero L, Stewart S. An epidemiological study of pulmonary arterial hypertension. Eur Respir J. 2007:30:104-9.

3. Sanchez O, Marié E, Lerolle U, Wermert D, Israël-Biel D, Meyer G. Pulmonary arterial hypertension in women. Rev Mal Respir. 2010;27:e79-87.

4. D'Alonzo GE, Barst RJ, Ayres SM, Bergofsky EH, Brundage BH, Detre KM, et al. Survival in patients with primary pulmonary hypertension. Results from a national prospective registry. Ann Intern Med. 1991;115:343-9.

5. Simonneau G, Gatzoulis MA, Adatia I, Celermajer D, Denton C, Ghofrani A, et al. Updated clinical classification of pulmonary hypertension. J Am Coll Cardiol. 2013;62:25s.

6. Soubrier F, Chung WK, Machado R, Grünig E, Aldred M, Geraci M, et al. Genetics and genomics of pulmonary arterial hypertension. J Am Coll Cardiol. 2013;62:25S.

7. Baloira A, Vilariño C, Leiro V, Valverde D. Mutations in the gene encoding bone morphogenetic protein receptor 2 in patients with idiopathic pulmonary arterial hypertension. Arch Bronconeumol. 2008;44(1):29-34.

8. Machado RD, Eickelberg O, Elliott G, Geraci MW, Hanaoka M, Loyd JE, et al. Genetics and genomics of pulmonary arterial hypertension. J Am Coll Cardiol. 2009;54 Suppl 1:S32-42.

9. Yang X, Long L, Reynolds PN, Morrell NW. Expression of mutant BMPR-II in pulmonary endothelial cells promotes apoptosis and a release of factors that stimulate proliferation of pulmonary arterial smooth muscle cells. Pulm Circ. 2011;1(1):103-11.

10. Pffar N, Szamalek-Hoegel J, Fischer C, Hinderhofer K, Nagel C, Eklken N, et al. Hemodynamic and clinical onset in patients with hereditary pulmonary arterial hypertension and BMPR2 mutations. Respir Res. 2011;12:99-109.

11. Ulrich S, Szamalek-Hoegel J, Hersberger M, Fischler M, García JS, Huber LC, et al. Sequence variants in BMPR2 and genes involved in the serotonin and nitric oxide pathways in idiopathic pulmonary arterial hypertension and chronic thromboembolic pulmonary hypertension: relation to clinical parameters and comparison with left heart disease. Respiration. 2010;79:279-87.

12. Pousada G, Baloira A, Vilariño C, Cifrián JM, Valverde D. Novel mutations in BMPR2, ACVRL1 and KCNA5 genes and hemodynamic parameters in patients with pulmonary arterial hypertension. PLoS ONE. 2014;9(6):e100261.

13. Pfarr N, Fischer C, Ehlken N, Becker-Grünig T, López-González V, Gorenflo M, et al. Hemodynamic and genetic analysis in children with idiopathic, heritable, and congenital heart disease associated pulmonary arterial hypertension. Respir Res. 2013;14:3-12.

14. Yu Y, Fantozzi I, Remillard CV, Landsberg JW, Kunichika N, Plastoshyn O, et al. Enhanced expression of transient receptor potential channels in idiopathic pulmonary arterial hypertension. PNAS. 2004;101(38):13861-6.

15. Xia $Y$, Yang XR, Fu Z, Paudel $O$, Abramowitz J, Birnbaumer $L$, et al. Classical transient receptor potential 1 and 6 contribute to hypoxic pulmonary hypertension through differential regulation of pulmonary vascular functions. Hypertension. 2014;63:173-80.

16. Alzoubi A, Almalouf P, Toba M, O'Neill K, Qian X, Francis M, et al. TRPC4 inactivation confers a survival benefit in severe pulmonary arterial hypertension. Am J Pathol. 2013;183:1779-88.

17. Weissmann N, Dietrich A, Fuchs B, Kalwa H, Ay M, Dumitrascu R, et al. Classical transient receptor potential channel 6 (TRPC6) is essential for hypoxic pulmonary vasoconstriction and alveolar gas exchange. Proc Natl Acad Sci U S A. 2006;103:19093-8.

18. Zhang Y, Lu W, Yang K, Xu L, Lai N, Tian L, et al. Bone morphogenetic protein 2 decreases TRPC expression, store-operated $\mathrm{Ca}(2+)$ entry, and basal $[\mathrm{Ca}(2+)] \mathrm{i}$ in rat distal pulmonary arterial smooth muscle cells. Am J Physiol Cell Physiol. 2013;304:C833-43. 
19. Yu Y, Keller SH, Remillard CV, Safrina O, Nicholson A, Zhang SL, et al. A functional single-nucleotide polymorphism in the TRPC6 gene promoter associated with idiopathic pulmonary arterial hypertension. Circulation. 2009:119:2313-22

20. Palatini P, Ceolotto G, Dorigatti F, Mos L, Santonastaso M, Bratti P, et al. Angiotensin II type 1 receptor gene polymorphism predicts development of hypertension and metabolic syndrome. Am J Hypertens. 2009;22:208-14.

21. Nie SJ, Wen-ru T, Bi-feng C, Jin L, Wen Z, Sheng-jun L, et al. Haplotype-based case-control study of the human AGTR1 gene and essential hypertension in Han Chinese subjects. Clin Biochem. 2010;43(3):253-8.

22. Chassagne C, Eddahibi S, Adamy C, Rideau D, Marotte F, Dubois-Randé J, et al. Modulation of angiotensin II receptor expression during development and regression of hypoxic pulmonary hypertension. Am J Respir Cell Mol Biol. 2000;22:323-32.

23. Li Y, Li X, Jia N, Guo S, Chu S, Niu W. Meta-analysis of the association between angiotensin II receptor, type 1 gene A1166C polymorphism and coronary artery disease in Chinese populations. J Renin Angiotensin Aldosterone Syst. 2013;14(1):82-90.

24. Gardier S, Vincent M, Lantelme P, Rial MO, Bricca G, Milon H. A1166C polymorphism of angiotensin II type 1 receptor, blood pressure and arterial stiffness in hypertension. J Hypertens. 2004;22:2135-42.

25. Chung WK, Deng L, Carroll JS, Mallory N, Diamond B, Rosenzweig EB, et al. Polymorphism in the angiotensin II type 1 receptor (AGTR1) is associated with age at diagnosis in pulmonary arterial hypertension. J Heart Lung Transplant. 2009;28:373-9.

26. Galié N, Hoeper MM, Humbert M, Torbicki A, Vachiery JL, Barbera JA, et al. Guidelines for the diagnosis and treatment of pulmonary hypertension. Eur Heart J. 2009:30(20):2493-537.

27. Jíra M, Závodná E, Honzíková N, Nováková Z, Vasků A, Izakovicová Hollá L, et al. Association of A1166C polymorphism in AT(1) receptor gene with baroreflex sensitivity. Physiol Res. 2010;59(4):517-28.

28. Inoue $\mathrm{R}$, Jensen $\mathrm{L}, \mathrm{SHI}$ J, Morita H, Nishida M, Honda A, et al. Transient receptor potential channels in cardiovascular function and disease. Circ Res. 2006;99:119-31.

29. Freichel M, Vennekens R, Olausson J, Stolz S, Philipp SE, WeiBgerber P, et al. Functional role of TRPC proteins in native systems: implications from knockout and knock-down studies. J Physiol. 2005:567.1:59-66.

30. Lu W, Ran P, Zhang D, Lai N, Zhong N, Wang J. Bone morphogenetic protein 4 enhances canonical transient receptor potential expression, store-operated $\mathrm{Ca}_{2}^{+}$entry, and basal $\left[\mathrm{Ca}_{2}\right]_{\mathrm{i}}$ in rat distal pulmonary arterial smooth muscle cells. Am J Physiol Cell Physiol. 2010;299:C1370-8.

31. Kunichika N, Landsberg JW, Yu Y, Kunichika H, Thistlethwaite PA, Rubin LJ, et al. Bosentan inhibits transient receptor potential channel expression in pulmonary vascular myocytes. Am J Respir Crit Care Med. 2004;170:1101-7.

32. Ogawa A, Firth AL, Yao W, Rubin LJ, Yuan JX-J. Prednisolone inhibits PDGFinduced nuclear translocation of NF-KB in human pulmonary artery smooth muscle cells. Am J Physiol Lung Cell Mol Physiol. 2008;295:L648-57.

33. Boney-Montoya J, Ziegler YS, Curtis CD, Montoya JA, Nardulli AM. Long-range transcriptional control of progesterone receptor gene expression. Mol Endocrinol. 2010;24(2):346-58

34. Xu M, Sham P, Ye Z, Lindpaintner K, He L. A 1166 C genetic variation of the angiotensin II type I receptor gene and susceptibility to coronary heart disease: collaborative of 53 studies with 20,435 cases and 23,674 controls. Atherosclerosis. 2010;213(1):30-2.

35. Sethupathy P, Borel C, Gagnebin M, Grant GR, Deutsch S, Elton TS, et al. Human microRNA-155 on chromosome 21 differentially interacts with its polymorphic target in the AGTR1 3' untranslated region: a mechanism for functional single-nucleotide polymorphisms related to phenotypes. Am J Hum Genet. 2007:81(2):405-13.

36. Haas U, Sczakiel G, Laufer SD. MicroRNA-mediated regulation of gene expression is affected by disease-associated SNPs within the 3'-UTR via altered RNA structure. RNA Biol. 2012;9(6):924-37.

37. Song S, Yamamura A, Yamamura H, Ayon RJ, Smith KA, Tang H, et al. Flow shear stress enhances intracellular $\mathrm{Ca}^{2+}$ signaling in pulmonary artery smooth muscle cells from patients with pulmonary arterial hypertension. Am J Physiol Cell Physiol. 2014;307(4):C373-83.

\section{Submit your next manuscript to BioMed Central and take full advantage of:}

- Convenient online submission

- Thorough peer review

- No space constraints or color figure charges

- Immediate publication on acceptance

- Inclusion in PubMed, CAS, Scopus and Google Scholar

- Research which is freely available for redistribution

Submit your manuscript at www.biomedcentral.com/submit 